DOI: 10.12957/demetra.2018.31920

\title{
Aceitabilidade sensorial e características físico-químicas de morangos desidratados com diferentes tratamentos
}

\section{Sensory acceptability and physico-chemical haracteristics of dehydrated strawberries with different treatments}

Vanessa Alves'

Francielle do Rocio da Luz'

Kélin Schwarz ${ }^{2}$

Renata Leia Demario Vieira'

Gabriela Datsch Bennemann'

Juliano Tadeu Vilela de Resende ${ }^{3}$

1 Universidade Estadual do Centro Oeste, Departamento de Nutrição. Guarapuava, PR, Brasil.

2 Universidade Federal do Triângulo Mineiro, Departamento de Nutrição. Uberaba, MG, Brasil.

${ }^{3}$ Universidade Estadual do Centro Oeste, Departamento de Agronomia. Guarapuava, PR, Brasil.

Correspondência / Correspondence

Kélin Schwarz

E-mail: kelinschwarz@hotmail.com

\section{Resumo}

A desidratação é uma alternativa viável para utilizar morangos que não possuem formato, tamanho ou cor adequados para a comercialização. Este estudo teve como objetivo avaliar a aceitação sensorial e características físico-químicas de morangos desidratados com diferentes tratamentos. Os tratamentos utilizados foram aplicados antes da secagem em estufa a $60^{\circ} \mathrm{C}$ e consistiram em $1-60 \%$ sacarose + ácido ascórbico; 2 - 60\% sacarose + ácido cítrico; 3 - 60\% sacarose + pectina; $4-80 \%$ sacarose + ácido ascórbico; 5 - 80\% sacarose + ácido cítrico; 6 $80 \%$ sacarose + pectina e 7 - tratamento controle (sem adição de sacarose e/ou ingrediente). Os tratamentos foram avaliados por meio de análise sensorial com escala hedônica com julgadores não treinados. Foram avaliados o teor de sólidos solúveis, acidez titulável, pH, coloração, ácido ascórbico, antocianinas e compostos fenólicos dos frutos desidratados. Os tratamentos osmóticos de $80 \%$ sacarose + ácido ascórbico ou pectina foram bem aceitos pelos provadores e mostraram-se melhores que o tratamento controle. O teor de sólidos solúveis variou entre os tratamentos e foi maior para os morangos tratados com $80 \%$ sacarose + pectina, também apresentando maior relação sólidos solúveis/ acidez titulável. O teor de compostos fenólicos, antocianinas e ácido ascórbico foi maior para os tratamentos $80 \%$ sacarose + pectina ou ácido ascórbico ou ácido cítrico, os quais também apresentaram coloração vermelha mais intensa. $\mathrm{O}$ morango desidratado com pré-tratamento $80 \%$ sacarose + ácido ascórbico 
ou pectina mostrou-se boa opção de agregação de valor a essa fruta, visto que apresentou boa aceitação e manutenção de compostos bioativos.

Palavras-chave: Fragaria x Ananassa Duch. Desidratação Osmótica. Análise Sensorial. Compostos Bioativos. Conservação.

\section{Abstract}

Dehydration is a viable alternative to using strawberries that are not proper for marketing because of their form, size or color. This study aimed to evaluate the sensory acceptability and physico-chemical characteristics of dehydrated strawberries with different treatments. The treatments were applied before drying at $60^{\circ} \mathrm{C}$ and consisted of: $1-60 \%$ sucrose + ascorbic acid; 2 - $60 \%$ sucrose + citric acid; 3 - $60 \%$ sucrose + pectin; $4-80 \%$ sucrose + ascorbic acid; $5-80 \%$ sucrose + citric acid; $6-80 \%$ sucrose + pectin and 7 - control treatment (without addition of sucrose and/or ingredient). The treatments were evaluated by sensory analysis with hedonic scale with untrained judges. The content of soluble solids, titratable acidity, $\mathrm{pH}$, color, ascorbic acid, anthocyanins, and phenolic compounds of dehydrated fruits was evaluated. The osmotic treatments of $80 \%$ sucrose + ascorbic acid or pectin were well accepted by the testers and were better than the control treatment. The soluble solids content varied among treatments and was higher for strawberries treated with $80 \%$ sucrose + pectin, which also had a higher soluble solids/titratable acidity ratio. The content of phenolic compounds, anthocyanins and ascorbic acid was higher for the treatments $80 \%$ sucrose + pectin or ascorbic acid or citric acid, which also showed a more intense red color. Dehydrated strawberry with pretreatment $80 \%$ sucrose + ascorbic acid or pectin seemed to be a good option for adding value to this fruit, since it had a good acceptance and maintenance of bioactive compounds.

Keywords: Fragaria x Ananassa Duch. Osmotic Dehydration. Sensory Analysis. Bioactive Compounds. Conservation.

\section{Introdução}

O morango (Fragaria x ananassa Duch) é um fruto muito valorizado e um dos mais consumidos no mundo; no entanto, é muito delicado e altamente perecível, pois é pouco resistente após a colheita. ${ }^{1,2}$ Esta olerícola é uma rica fonte de compostos bioativos, como a vitamina C, carotenoides e compostos fenólicos (ácidos fenólicos, flavonoides e antocianinas). ${ }^{3,4}$ 
O interesse comercial pelo morango é grande em muitos países, devido a sua coloração, aroma, sabor e propriedades nutricionais, que fazem dele um produto de elevado valor comercial e muito apreciado pelos consumidores. ${ }^{5}$ No Brasil, a produção nacional chega a 105 mil toneladas por ano, a maior parte obtida em pequenas propriedades rurais. ${ }^{6}$ Entretanto, estima-se que cerca de $40 \%$ desta produção seja perdida devido à alta perecibilidade do fruto. ${ }^{7,8}$

O mercado para o morango é bastante atrativo, visto que além da produção primária, para consumo dos frutos in natura, essa cultura é de grande importância para a agroindústria, sendo matéria-prima para a produção de sorvetes, bebidas lácteas, doces, licores, geleias, entre outros. ${ }^{9} \mathrm{~A}$ comercialização dos frutos in natura, no entanto,tem como limitante a rápida perda de qualidade pós-colheita, ${ }^{10,11}$ sendo a vida útil do morango fresco de aproximadamente cinco dias quando mantido a baixas temperaturas $\left(0\right.$ a $\left.4^{\circ} \mathrm{C}\right) .^{2,12}$

Considerando a perecibilidade do morango e o fato de poder ser estocado por poucos dias, ${ }^{13}$ há a necessidade da utilização de tecnologia adequada para melhorar a conservação e o tempo de prateleira dos frutos. Uma das opções de conservação é o processo de secagem, que pode ser realizado por meio de vários métodos, os quais removem parte da água do alimento, diminuindo a deterioração por micro-organismos e alterações químicas e enzimáticas. ${ }^{14}$

A desidratação é uma técnica que consiste na eliminação de água por evaporação, com transferência de calor e massa, em que o sólido a ser seco é exposto a uma corrente de ar quente que flui continuamente e, assim, a umidade é removida. ${ }^{15} \mathrm{~A}$ diminuição da quantidade de água pela secagem reduz a atividade biológica e as mudanças físico-químicas pós-colheita do produto final, melhorando a estabilidade. Esse processo ainda agrega valor ao produto acabado e diminui os desperdícios. ${ }^{16}$

Os alimentos desidratados são produtos comerciais de grande aceitação, pois têm o tempo de conservação aumentado sem perder muito de suas propriedades organolépticas e nutricionais. ${ }^{17}$ De acordo com o Instituto Brasileiro de Geografia e Estatística (IBGE), ${ }^{18}$ a produção de frutas secas desidratadas ou liofilizadas saltou de 11,1 milhões para 26,8 milhões de quilogramas entre os anos de 2010 e 2011, demonstrando grande crescimento no setor. Entretanto, ao ser submetido ao processo de secagem, os frutos podem perder compostos de interesse nutricional ou mesmo características físico-químicas importantes.

Nesse sentido, e devido à constante necessidade de inovação para o fortalecimento da agricultura familiar na oferta de alimentos, o objetivo deste estudo foi desenvolver morangos desidratados com diferentes tratamentos e avaliar sua aceitabilidade sensorial e características físico-químicas, de modo a determinar o melhor tratamento para um produto final de qualidade e com menor perda de compostos de interesse nutricional. 


\section{Material e Métodos}

Os morangos foram obtidos do comércio local de Guarapuava-PR. Foram utilizados aqueles que estavam em estádio maduro, caracterizado pela coloração vermelho brilhante.

\section{Elaboração dos morangos desidratados}

Os frutos foram selecionados, a coroa (parte verde) foi retirada e eles foram lavados em água corrente, sendo e depois imersos em solução de hipoclorito de sódio (150 mg L $\left.\mathrm{L}^{-1}\right)$ por 15 minutos, para desinfecção. Após, foram secados à temperatura ambiente. Depois de limpas, as amostras foram cortadas em rodelas com auxílio de uma faca inox, de modo a facilitar a secagem.

O processo de secagem foi realizado no laboratório de Produção Vegetal - Olericultura, do Departamento de Agronomia da Universidade Estadual do Centro-Oeste, com auxílio de uma estufa de secagem com circulação forçada de ar.

\section{Tratamentos}

Selecionou-se $1,5 \mathrm{~kg}$ de morangos para cada tratamento. Os tratamentos consistiram de desidratação osmótica com solução de sacarose nas concentrações de $60 \%$ e $80 \%$ por duas horas, seguida de adição de um dos ingredientes conservadores: ácido cítrico, ácido ascórbico ou pectina.

Após esses procedimentos, os frutos foram dispostos em bandejas e secos em estufa a $60^{\circ} \mathrm{C}$ por seis horas ou até obter um produto com umidade inferior a $25 \% .^{19}$ Sendo assim, foram obtidos sete tratamentos, conforme descrição detalhada que segue:

- T1: desidratação osmótica com solução de sacarose 60\% + imersão em ácido ascórbico a $1 \%$ por 2 minutos + secagem a $60^{\circ} \mathrm{C}$ por 6 horas;

- T2: desidratação osmótica com solução de sacarose 60\% + imersão em ácido cítrico a $1 \%$ por 2 minutos + secagem a $60^{\circ} \mathrm{C}$ por 6 horas;

- T3: desidratação osmótica com solução de sacarose $60 \%$ + imersão em pectina a $2 \%$ por 15 minutos + secagem a $60^{\circ} \mathrm{C}$ por 6 horas;

- T4: desidratação osmótica com solução de sacarose 80\% + imersão em ácido ascórbico a $1 \% 2$ minutos + secagem a $60^{\circ} \mathrm{C}$ por 6 horas;

- T5: desidratação osmótica com solução de sacarose $80 \%$ + imersão em ácido cítrico a $1 \%$ por 2 minutos + secagem a $60^{\circ} \mathrm{C}$ por 6 horas; 
- T6: desidratação osmótica com solução de sacarose $80 \%$ + imersão em pectina a $2 \%$ por 15 minutos + secagem a $60^{\circ} \mathrm{C}$ por 6 horas;

- T7: desidratação dos frutos apenas por secagem a $60^{\circ} \mathrm{C}$ por 6 horas (tratamento controle).

As soluções de sacarose, ácido cítrico, ácido ascórbico e pectina foram preparadas com água destilada e respeitando as condições adequadas de higiene e boas práticas de fabricação.

Após a secagem em estufa, os morangos foram acondicionados em embalagens plásticas devidamente fechadas e identificadas até o momento das análises.

\section{Análise sensorial}

Os testes sensoriais foram conduzidos no Laboratório de Análise Sensorial do Departamento de Engenharia de Alimentos da Universidade Estadual do Centro-Oeste, em cabines individuais com iluminação de cor branca.

Participaram da pesquisa 68 provadores não treinados, entre alunos, professores e funcionários da instituição, de ambos os sexos, com idade mínima de 18 anos e sem vínculo de subordinação com os pesquisadores. Para o recrutamento dos mesmos, realizou-se abordagem pelos pesquisadores para o convite em forma oral.

Todos os participantes receberam os sete tratamentos de desidratação dos morangos e avaliaram as amostras quanto aos atributos cor, sabor, textura, aroma e aceitação global, mediante escala hedônica estruturada de nove pontos, variando de desgostei muitíssimo (nota 1) a gostei muitíssimo (nota 9), segundo metodologia de Dutcosky. ${ }^{20}$ Para o teste de intenção de compra, foi utilizada escala de cinco pontos ancorada em seus extremos com os termos: 1 - certamente não compraria a 5 - certamente compraria.

Cada julgador recebeu um pedaço de cada amostra em pratos plásticos brancos, codificados com números de três dígitos, de forma casualizada, acompanhados de água para ser utilizada entre cada prova. As amostras foram oferecidas aos julgadores de forma monádica sequencial.

\section{Índice de aceitabilidade (IA)}

O cálculo do IA dos tratamentos foi realizado segundo a fórmula: $I A(\%)=A \times 100 / B(A=$ nota média obtida para o produto; $B=$ nota máxima dada ao produto).${ }^{20} \mathrm{O}$ tratamento foi considerado bem aceito quando o IA foi maior ou igual a $70 \%{ }^{21}$ 


\section{Acidez titulável}

A acidez titulável foi realizada em triplicata e de acordo com a Association of Official Analytical Chemists (AOAC), ${ }^{22}$ por meio de titulação com hidróxido de sódio $0,1 \mathrm{~mol} \mathrm{~L}^{-1}$ até $\mathrm{pH} 8,1$. Os resultados foram expressos em gramas de ácido cítrico $100 \mathrm{~g}^{-1}$ amostra.

\section{Sólidos solúveis}

O teor de sólidos solúveis foi verificado em triplicata em refratômetro de bancada com duas a três gotas do filtrado da amostra. Os resultados foram expressos em ${ }^{\circ}$ Brix. O filtrado foi obtido pela solubilização das amostras desidratadas em volume conhecido de água destilada (proporção 1:3, m/v).

\section{Relação sólidos solúveis/acidez titulável}

A relação SS/AT (ratio) foi calculada a partir dos dados obtidos para teor de sólidos solúveis e acidez titulável.

$\mathrm{pH}$

$\mathrm{O}$ pH foi determinado em triplicata, em temperatura ambiente com auxílio de pHmetro em amostras diluídas em água.

\section{Compostos fenólicos e antocianinas}

O conteúdo de compostos fenólicos foi determinado pelo método de Folin-Ciocalteau, de acordo com o descrito por Woisky \& Salatino, ${ }^{23}$ em espectrofotômetro a $740 \mathrm{~nm}$. Os resultados foram expressos em mg de ácido gálico por 100 gramas de amostra.

$\mathrm{O}$ teor de antocianinas foi determinado pelo método diferencial de $\mathrm{pH}$ descrito por Giusti \& Wrolstad. ${ }^{24} \mathrm{O}$ método baseia-se em dois sistemas-tampão, o cloreto de potássio $0,025 \mathrm{M}, \mathrm{pH} 1,0$ e o acetato de sódio 0,4 M, pH 4,5. As amostras foram analisadas a 510 e $700 \mathrm{~nm}$ em espectrofotômetro, e os resultados expressos em mg de cianidina-3-glicosídeo por 100 gramas de amostra.

Os extratos para a análise dos compostos fenólicos e antocianinas foram preparados através da percolação da amostra homogeneizada com solução de etanol:água (80:10, v/v) na proporção 1:15 (amostra:solvente). Estes procedimentos foram realizados em ambiente com pouca iluminação. 
A extração foi realizada em mesa agitadora à temperatura ambiente, por 30 minutos a $135 \mathrm{rpm}$, seguida de banho-maria a $37^{\circ} \mathrm{C}$ por $30 \mathrm{~min}$. O extrato resultante foi centrifugado a $2235,7 \mathrm{~g}$ por 10 minutos. Em seguida, o sobrenadante foi filtrado e este utilizado para as análises.

\section{Ácido ascórbico}

O teor de ácido ascórbico foi determinado pelo método titulométrico da AOAC ${ }^{22}$ modificado por Benassi \& Antunes, ${ }^{25}$ e os resultados expressos em mg de ácido ascórbico por 100 gramas de amostra.

\section{Coloração}

As alterações de cor foram determinadas utilizando-se colorímetro Minolta com iluminante D65. Foram obtidos os valores de $\mathrm{L}^{*}, \mathrm{a}^{*}$ e $\mathrm{b}^{*}$; onde $\mathrm{L}$ representa a luminosidade, $\mathrm{a}^{*}$ define a transição da cor verde (-a*) para a cor vermelha $\left(+a^{*}\right)$ e b* representa a transição da cor azul $\left(-b^{*}\right)$ para a cor amarela $\left(+b^{*}\right)$. Os valores do ângulo-hue $\left({ }^{\circ} \mathrm{H}\right)$ foram calculados de acordo com a fórmula: ${ }^{\circ} \mathrm{H}=\operatorname{tg}-1\left(b^{*} / a^{*}\right)$.

Foram realizadas leituras em três pontos distintos das amostras. A análise ocorreu em local com alta luminosidade e em triplicata.

\section{Análise estatística}

A análise estatística foi realizada por meio do software SAS 9.0. Os dados foram submetidos a análise de normalidade (Shapiro-Wilk) e homogeneidade das variâncias (Box-Cox) e posteriormente submetidos à análise de variância (ANOVA).

Os dados obtidos da análise sensorial foram submetidos a ANOVA em blocos casualizados, em que cada provador representa um bloco. Já as análises de caracterização físico-química foram realizadas em delineamento inteiramente casualizado com três repetições. Quando os resultados do teste F (ANOVA) foram significativos, as médias foram comparadas pelo teste de Tukey $(\mathrm{p}<0,05)$.

\section{Questões éticas}

Este trabalho foi aprovado pelo Comitê de Ética em Pesquisa da Universidade Estadual do Centro-Oeste, sob parecer número 1.639.854/2016. Os critérios de exclusão foram: ser menor de 18 anos, alegar alguma alergia aos produtos que foram avaliados ou não permitir divulgação de seus resultados, nem seu uso no presente estudo. 


\section{Resultados e Discussão}

Na tabela 1, estão apresentados os resultados da avaliação sensorial dos morangos desidratados com diferentes tratamentos.

Tabela 1. Médias dos testes sensoriais afetivos, intenção de compra (médias \pm desvio padrão) e índice de aceitabilidade (IA) realizados para os morangos desidratados sob diferentes tratamentosl. Guarapuava-PR, 2016.

\begin{tabular}{|c|c|c|c|c|c|c|}
\hline \multirow[b]{2}{*}{ Tratamentos } & \multicolumn{6}{|c|}{ Atributos } \\
\hline & Cor & Aroma & Sabor & Textura & $\begin{array}{c}\text { Aceitação } \\
\text { global }\end{array}$ & $\begin{array}{l}\text { Intenção de } \\
\text { compra }\end{array}$ \\
\hline Controle & $5,7 \pm 1,4^{\mathrm{c}}$ & $6,6 \pm 1,9 \mathrm{ab}$ & $6,1 \pm 1,9^{\text {a }}$ & $6,4 \pm 2,2$ ab & $6,3 \pm 1,7$ bc & $3,0 \pm 1,2^{\mathrm{d}}$ \\
\hline $\mathrm{IA}(\%)$ & 71,7 & 73,0 & 68,0 & 71,1 & 70,1 & 59,4 \\
\hline $80 \%+$ ac. cítrico & $6,1 \pm 1,8 \mathrm{bc}$ & $6,8 \pm 2,1$ ab & $6,1 \pm 2,4^{\mathrm{a}}$ & $6,2 \pm 2,4$ ab & $6,4 \pm 2,1 \mathrm{abc}$ & $3,4 \pm 1,3 \mathrm{bcd}$ \\
\hline $\mathrm{IA}(\%)$ & 67,5 & 75,2 & 67,8 & 69,1 & 70,9 & 67,1 \\
\hline $80 \%+$ ac. ascórbico & $7,5 \pm 1,7^{\mathrm{a}}$ & $7,2 \pm 1,7^{\mathrm{a}}$ & $6,8 \pm 1,9^{a}$ & $7,0 \pm 1,9^{\mathrm{a}}$ & $7,2 \pm 1,7^{\mathrm{a}}$ & $4,5 \pm 0,7^{a}$ \\
\hline $\mathrm{IA}(\%)$ & 83,8 & 80,1 & 75,8 & 78,3 & 79,7 & 90,3 \\
\hline $80 \%+$ pectina & $7,7 \pm 1,4^{\mathrm{a}}$ & $7,3 \pm 1,5^{\mathrm{a}}$ & $6,7 \pm 1,6^{\mathrm{a}}$ & $6,8 \pm 1,8^{\text {a }}$ & $7,0 \pm 1,3 \mathrm{ab}$ & $3,7 \pm 1,1^{b}$ \\
\hline $\mathrm{IA}(\%)$ & 85,3 & 80,7 & 74,8 & 75,0 & 77,9 & 74,1 \\
\hline $60 \%+$ ac. cítrico & $6,2 \pm 1,8^{\mathrm{bc}}$ & $6,1 \pm 2,1^{\mathrm{b}}$ & $6,1 \pm 2,0^{\text {a }}$ & $5,5 \pm 2,3^{\mathrm{b}}$ & $6,1 \pm 1,8^{c}$ & $3,1 \pm 1,0^{\mathrm{cd}}$ \\
\hline $\mathrm{IA}(\%)$ & 68,5 & 68,0 & 67,6 & 61,1 & 68,0 & 62,6 \\
\hline $60 \%+$ ac. ascórbico & $6,6 \pm 1,8^{\mathrm{b}}$ & $6,3 \pm 1,9^{b}$ & $6,5 \pm 1,6^{\mathrm{a}}$ & $6,6 \pm 1,9^{\text {a }}$ & $6,4 \pm 1,7 \mathrm{abc}$ & $3,5 \pm 1,3 \mathrm{bcc}$ \\
\hline $\mathrm{IA}(\%)$ & 73,4 & 70,4 & 71,7 & 73,9 & 71,2 & 69,7 \\
\hline $60 \%+$ pectina & $8,3 \pm 1,2^{a}$ & $6,8 \pm 1,7$ ab & $6,5 \pm 1,7$ a & $6,4 \pm 2,1 \mathrm{ab}$ & $6,6 \pm 1,6 \mathrm{abc}$ & $3,7 \pm 1,1^{b c}$ \\
\hline IA $(\%)$ & 91,7 & 75,8 & 72,2 & 71,4 & 73,9 & 73,2 \\
\hline
\end{tabular}

${ }^{1}$ Letras diferentes na coluna indicam diferença significativa pelo teste de Tukey $(\mathrm{p}<0,05) ; 80 \%=80 \%$ de sacarose; $60 \%=60 \%$ de sacarose.

Para o atributo cor, os tratamentos $80 \%$ sacarose + ácido ascórbico, $80 \%$ sacarose + pectina e $60 \%$ sacarose + pectina foram os mais aceitos, com notas 7,5, 7,7 e 8,3, respectivamente, não havendo diferença significativa entre eles $(\mathrm{p}>0,05)$. Já o tratamento menos aceito foi o controle, que recebeu nota média de 5,7 e IA de 71,7\%. Contudo, o tratamento controle não diferiu do tratamento $80 \%$ sacarose + ácido cítrico e do tratamento $60 \%$ sacarose + ácido cítrico para a cor. 
Essa diferença entre os tratamentos está relacionada ao fato de a cor influenciar na aceitabilidade do produto ${ }^{20}$ e também pelos ingredientes como ácido ascórbico e pectina, que quando adicionados reduziram as reações de escurecimento das frutas, provavelmente preservando a cor. ${ }^{26}$ Além disso, os tratamentos que obtiveram maiores notas em relação a cor também apresentaram teores mais elevados de antocianinas e compostos fenólicos (tabela 3). Sabe-se que estes compostos estão relacionados a coloração do morango, ${ }^{27}$ e quando presentes em maiores quantidades, podem intensificar a cor, favorecendo este atributo sensorial.

Em relação ao atributo aroma, somente um dos tratamentos recebeu IA inferior ao considerado com boa aceitação sensorial (70\%), sendo o tratamento 60\% sacarose + ácido ascórbico com IA de $68 \%$ e nota 6,1 . A maior nota ficou com o tratamento $80 \%$ sacarose + pectina, com 7,3 e IA de 80,75.

Quanto ao sabor, o tratamento $80 \%$ sacarose + ácido ascórbico obteve nota 6,8, com IA de $75,8 \%$, sendo o mais aceito sensorialmente. Já os tratamentos controle, $80 \%$ sacarose + ácido cítrico e o $60 \%$ sacarose + ácido cítrico receberam notas baixas e foram os menos aceitos. Com base nas notas para textura, o tratamento $60 \%$ sacarose + ácido cítrico obteve as menores notas, diferindo apenas dos tratamentos $80 \%$ sacarose + ácido ascórbico, $80 \%$ sacarose + pectina e $60 \%$ sacarose + ácido ascórbico.

O tratamento com maior aceitação global foi $80 \%$ sacarose + ácido ascórbico, com média de 7,2 e IA de 79,7\%. Entretanto, este tratamento não diferiu estatisticamente dos tratamentos $80 \%$ sacarose + ácido cítrico, $80 \%$ sacarose + pectina, $60 \%$ sacarose + ácido ascórbico e $60 \%$ sacarose + pectina. Já os morangos desidratados com a menor aceitação global foram aqueles tratados com $60 \%$ sacarose + ácido cítrico, com média de 6,1 e IA de $68 \%$.

Em se tratando de intenção de compra, o tratamento com maior nota foi $80 \%$ sacarose + ácido ascórbico, com nota média de 4,5 e IA de 90,3\%. Já o que obteve a nota menor foi o controle, com média de 3,0 e IA de $59,4 \%$.

De forma geral, o tratamento $80 \%$ sacarose + ácido ascórbico e o $80 \%$ sacarose + pectina foram os que receberam médias altas e bom IA (\%) em praticamente todos os atributos. É provável que, o motivo dessa escolha tenha sido o realce de cor da fruta desidratada causado pelo uso de ácido ascórbico e pectina + sacarose, ${ }^{26,28}$ além da boa combinação de sabor, aroma e textura. Em contrapartida, o tratamento $60 \%$ sacarose + ácido cítrico não atingiu $70 \%$ de IA em nenhum dos atributos. Isto pode ser justificado pelo fato de o ácido cítrico acabar acidificando o sabor do morango. ${ }^{29}$

Estudo realizado por Basílio et al., ${ }^{7}$ para avaliar a aceitação de iogurte com adição de morangos desidratados com 28 julgadores, verificou que $64 \%$ dos avaliadores gostaram do sabor do produto, $68 \%$ do aroma e $54 \%$ comprariam o produto, demonstrando o potencial de morangos desidratados. No estudo realizado por Balke et al., ${ }^{30}$ com pêssegos obtidos por 
diferentes métodos de secagem, houve boa aceitação geral para os tratamentos realizados com desidratação osmótica, estufa e liofilização.

Na tabela 2, estão apresentados os valores encontrados para o teor de sólidos solúveis, acidez titulável e pH dos morangos.

Tabela 2. Teor de sólidos solúveis (SS) ( ${ }^{\circ}$ Brix), acidez titulável (AT) (mg ácido cítrico 100 $\mathrm{g}^{-1}$ ), relação SS/AT e pH (média \pm desvio padrão) de morangos desidratados sob diferentes tratamentos ${ }^{1}$. Guarapuava-PR, 2016.

\begin{tabular}{|c|c|c|c|c|}
\hline Tratamento & $\begin{array}{c}\text { Sólidos solúveis } \\
\left({ }^{\circ} \text { Brix }\right)\end{array}$ & $\begin{array}{c}\text { Acidez titulável } \\
\quad\left({\left.\mathrm{g} 100 \mathrm{~g}^{-1}\right)}\right.\end{array}$ & Relação SS/AT & $\mathrm{pH}$ \\
\hline Controle & $9,1 \pm 0,1^{\mathrm{c}}$ & $3,5 \pm 0,05^{\mathrm{d}}$ & $2,59 \pm 0,05^{b}$ & $3,72 \pm 0,03$ a \\
\hline $80 \%$ + ac cítrico & $10,7 \pm 0,1^{b}$ & $4,2 \pm 0,09^{c}$ & $2,52 \pm 0,03 \mathrm{bc}$ & $3,45 \pm 0,02^{b}$ \\
\hline $80 \%+$ ac ascórbico & $10,4 \pm 0,4^{b}$ & $4,7 \pm 0,02^{a}$ & $2,22 \pm 0,09^{\mathrm{d}}$ & $3,35 \pm 0,01^{d}$ \\
\hline $80 \%+$ pectina & $12,4 \pm 0,3^{\mathrm{a}}$ & $4,2 \pm 0,02^{\mathrm{c}}$ & $2,94 \pm 0,08^{a}$ & $3,39 \pm 0,01^{\mathrm{cd}}$ \\
\hline $60 \%+$ ac. Cítrico & $10,3 \pm 0,1^{b}$ & $4,4 \pm 0,04^{\mathrm{b}}$ & $2,33 \pm 0,01{ }^{c d}$ & $3,24 \pm 0,01^{\mathrm{e}}$ \\
\hline $60 \%+$ ac ascórbico & $9,3 \pm 0,4^{c}$ & $4,2 \pm 0,04^{\mathrm{c}}$ & $2,20 \pm 0,09^{\mathrm{d}}$ & $3,37 \pm 0,01^{\mathrm{d}}$ \\
\hline $60 \%+$ pectina & $10,2 \pm 0,4^{b}$ & $4,6 \pm 0,04^{\mathrm{a}}$ & $2,220,07 \mathrm{~d}$ & $3,42 \pm 0,01 \mathrm{bc}$ \\
\hline
\end{tabular}

${ }^{1}$ Letras diferentes na coluna indicam diferença significativa pelo teste de Tukey $(\mathrm{p}<0,05) ; 80 \%=80 \%$ de sacarose; $60 \%=60 \%$ de sacarose.

No que diz respeito ao teor de sólidos solúveis, observa-se que o maior ganho de sólidos se deu para o tratamento com $80 \%$ sacarose + pectina, que diferiu dos demais $\left(12,4{ }^{\circ} \mathrm{Brix}\right)$. Talvez isso tenha ocorrido pela quantidade de pectina absorvida pelo fruto, a qual, por ser solúvel, foi contabilizada na análise de sólidos solúveis. Diferentemente do presente estudo, Campo ${ }^{26}$ demonstrou que houve maior diferença entre as concentrações de 60 e $80 \%$ de sacarose em relação

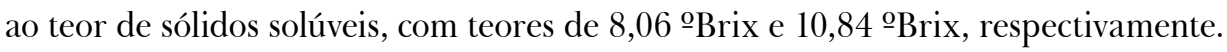

Os componentes mais abundantes e que fazem parte dos sólidos solúveis (xilitol, sorbitol e xilose) estão relacionados à doçura do morango. ${ }^{31}$ De acordo com Kader, ${ }^{32}$ o morango in natura possui teor de sólidos solúveis totais entre 4,1 e 11,9 ${ }^{\circ} \mathrm{Brix}$, dependendo da cultivar e dos fatores pré-colheita. No presente estudo, os morangos apresentavam ${ }^{\circ}$ Brix inicial (in natura) em torno de 5,0, e além da concentração dos açúcares presentes no fruto após a desidratação, houve adição de açúcar na forma de solução de sacarose, o que elevou ainda mais o teor de sólidos solúveis.

A acidez titulável é um indicador da quantidade de ácidos orgânicos presentes no fruto, sendo importante para as características sensoriais, pois agrega sabor. ${ }^{33}$ No presente estudo, os maiores valores de acidez titulável foram encontrados para tratamentos com $80 \%$ sacarose + ácido ascórbico 
e $60 \%$ sacarose + pectina, com 4,7 e 4,6 g $100 \mathrm{~g}^{-1}$, respectivamente. O menor valor foi observado para o tratamento controle, com 3,5 g $100 \mathrm{~g}^{-1}$. Os tratamentos com $80 \%$ sacarose + ácido cítrico, $80 \%$ sacarose + pectina e $60 \%$ sacarose + ácido ascórbico não diferiram entre si.

A relação entre os sólidos solúveis e a acidez titulável (SS/AT) é de suma importância para a análise sensorial, pois demonstra o balanço entre açúcar e acidez, determinando o sabor dos frutos. ${ }^{34} \mathrm{O}$ maior valor encontrado para a relação SS/AT se deu para o tratamento com $80 \%$ sacarose + pectina $(2,94)$, um dos mais bem aceitos sensorialmente. Entretanto, percebe-se que este fator (relação SS/AT) não é o único determinante da aceitação sensorial dos provadores, uma vez que o tratamento $80 \%$ sacarose + ácido ascórbico, mesmo com baixos valores para a relação SS/AT $(2,22)$, teve boa aceitação.

$\mathrm{O}$ pH é um dos fatores que exerce maior efeito seletivo sobre o desenvolvimento da microflora nos alimentos. ${ }^{35} \mathrm{O}$ maior valor de $\mathrm{pH}$ encontrado foi no tratamento controle $(3,72)$, e o menor no tratamento com $60 \%$ sacarose + ácido ascórbico (3,37). Os tratamentos com $80 \%$ sacarose + ácido ascórbico $(3,35)$ e com $60 \%$ sacarose + ácido ascórbico (3,37) obtiveram valores semelhantes e não diferiram do tratamento com $80 \%$ sacarose + pectina. No estudo realizado por Guimarães, ${ }^{33}$ observou-se $\mathrm{pH}$ de 3,81 para morango desidratado, valor semelhante aos encontrados na presente pesquisa.

A tabela 3 apresenta os teores de compostos fenólicos totais, antocianinas e ácido ascórbico de morangos desidratados com diferentes tratamentos.

Tabela 3. Teor de compostos fenólicos ( $\mathrm{mg}$ ácido gálico $\left.100 \mathrm{~g}^{-1}\right)$, teor de antocianinas (mg cianidina 3-glicosídeo $100 \mathrm{~g}^{-1}$ ) e teor de ácido ascórbico (mg ácido ascórbico $100 \mathrm{~g}^{-1}$ ) (média \pm desvio padrão) de morangos desidratados com diferentes tratamentos ${ }^{1}$. Guarapuava-PR, 2016.

\begin{tabular}{|c|c|c|c|}
\hline Tratamento & $\begin{array}{l}\text { Fenólicos } \\
\left(\mathrm{mg} 100 \mathrm{~g}^{-1}\right)\end{array}$ & $\begin{array}{c}\text { Antocianinas } \\
\left(\mathrm{mg} 100 \mathrm{~g}^{-1}\right)\end{array}$ & $\begin{array}{l}\text { Ácido ascórbico } \\
\quad\left(\mathrm{mg} 100 \mathrm{~g}^{-1}\right)\end{array}$ \\
\hline Controle & $105,8 \pm 6,2^{\mathrm{d}}$ & $11,4 \pm 1,3^{\mathrm{e}}$ & $33,8 \pm 2,6^{\mathrm{e}}$ \\
\hline $80 \%+$ ac cítrico & $221,7 \pm 5,4^{\mathrm{a}}$ & $56,4 \pm 3,9^{\mathrm{b}}$ & $88,4 \pm 1,5^{\mathrm{a}}$ \\
\hline $80 \%+$ ac ascórbico & $221,9 \pm 3,6^{\mathrm{a}}$ & $50,7 \pm 3,2^{\mathrm{c}}$ & $79,1 \pm 0,9^{\mathrm{b}}$ \\
\hline $80 \%+$ pectina & $220,6 \pm 3,2^{\mathrm{a}}$ & $68,1 \pm 3,9^{a}$ & $81,5 \pm 2,6^{b}$ \\
\hline $60 \%+$ ac cítrico & $193,2 \pm 7,8^{c}$ & $25,5 \pm 1,6^{\mathrm{d}}$ & $55,3 \pm 3,5^{c}$ \\
\hline $60 \%+$ ac ascórbico & $215,6 \pm 4,9^{a}$ & $51,0 \pm 1,9^{\mathrm{c}}$ & $60,1 \pm 0,6^{c}$ \\
\hline $60 \%+$ pectina & $202,5 \pm 8,9^{b}$ & $60,6 \pm 3,5^{\mathrm{b}}$ & $44,7 \pm 0,7^{\mathrm{d}}$ \\
\hline
\end{tabular}

${ }^{1}$ Letras diferentes na coluna indicam diferença significativa pelo teste de Tukey $(\mathrm{p}<0,05) ; 80 \%=80 \%$ de sacarose; $60 \%=60 \%$ de sacarose. Resultados em base seca. 
Uma das principais características da desidratação osmótica é a penetração de solutos na amostra, sendo possível modificar, de certa forma, sua formulação, através da adição de agentes redutores de atividade de água, ingredientes ou aditivos como antioxidantes e outros conservantes ao alimento, conservando-se assim os compostos bioativos de interesse nutricional ou sensorial. ${ }^{36,37}$

Em geral, o pré-tratamento osmótico seguido da desidratação conservou e concentrou os compostos bioativos no morango, provavelmente pelo fato de a desidratação causar poucas alterações no alimento, sendo algumas esperadas, como a perda de água e a concentração dos nutrientes por unidade de massa. ${ }^{38}$ Isto ocorreu porque nesse processo há a diferença de concentração entre o agente osmótico e o morango, imerso em solução, de sacarose, mais os agentes conservadores, com atividade de água menor que o alimento. ${ }^{26}$

Além disso, a baixa temperatura de secagem utilizada $\left(60^{\circ} \mathrm{C}\right)$ pode ter contribuído para que esses compostos se mantivessem, uma vez que a secagem convencional combinada ao prétratamento osmótico pode obter maior retenção da cor natural do produto e preservação de componentes voláteis. ${ }^{39}$

El-Aquar \& Murr $^{40}$ observaram que o emprego de ácido cítrico em solução de sacarose $70^{\circ}$ Brix, como pré-tratamento osmótico em mamões, promoveu menor ganho de sólidos e maior perda de água, preservando assim compostos bioativos como a vitamina C e carotenoides, uma vez que estes aditivos previnem a degradação por oxidação dos compostos presentes em frutas. Já a sacarose parece reger o processo de transferência de massa, visto que se encontra em maior quantidade em relação aos demais ingredientes adicionados, ou seja, quando maior a concentração da solução, ocorrem a perda de água e o ganho de sólidos.

O teor de compostos fenólicos foi maior para os tratamentos $80 \%$ sacarose + ácido cítrico, $80 \%$ sacarose + ácido ascórbico, $80 \%$ sacarose + pectina e $60 \%$ sacarose + ácido ascórbico, os quais não diferiram entre si. Já o tratamento controle apresentou o menor teor de compostos fenólicos. Isso demonstra que altos teores de açúcar e a presença de ácido (ascórbico ou cítrico) provavelmente apresentam efeito protetor para compostos fenólicos totais na desidratação.

Mendes et al. ${ }^{41}$ verificaram resultados satisfatórios ao submeter laranjas ao processo de desidratação osmótica com solução de sacarose $70 \%$ e adição de ácido cítrico e ácido ascórbico, seguido da secagem convencional a $65^{\circ} \mathrm{C}$. Em seu estudo, as laranjas que receberam o prétratamento osmótico apresentaram melhores resultados quanto aos teores de compostos fenólicos $\left(4,0 \mathrm{mg} 100 \mathrm{~g}^{-1}\right)$ em relação às laranjas desidratadas sem o tratamento $\left(1,7 \mathrm{mg} 100 \mathrm{~g}^{-1}\right)$. Portanto, o pré-tratamento osmótico foi eficaz na retenção dos compostos fenólicos presentes na laranja, corroborando os resultados deste estudo. 
O teor de antocianinas se mostrou mais concentrado nos tratamentos com adição de pectina + sacarose $80 \%$, pectina + sacarose $60 \%$, ácido cítrico $+80 \%$ sacarose, ácido ascórbico + sacarose $60 \%$ e ácido ascórbico $+80 \%$ sacarose. Já o tratamento controle e o tratamento ácido cítrico + $60 \%$ sacarose apresentaram menores teores de antocianinas. Shigematsu et al. ${ }^{42}$ sugerem que a adição de pectina aumenta a resistência do tecido da fruta, reduzindo a transferência de sacarose, que age como agente conservador. Com isso, a própria cobertura de pectina fica impregnada, tornando a fruta mais concentrada, preservando assim as antocianinas e mantendo sua cor.

Durante o processo térmico, pode ocorrer a degradação das antocianinas, como observado no tratamento controle e no tratamento com ácido cítrico $+60 \%$ sacarose. No presente estudo, entretanto, observaram-se valores que demonstram a conservação destas em alguns tratamentos, que, como no caso dos fenólicos totais, podem ter sido preservadas pela alta concentração de sacarose em combinação com os agentes adicionados.

Os teores de ácido ascórbico foram mais concentrados nos tratamentos com adição de ácidos e pectina em relação ao tratamento controle, sendo que o tratamento $80 \%$ sacarose + ácido cítrico foi o que apresentou o maior teor $\left(88,4 \mathrm{mg} 100 \mathrm{~g}^{-1}\right)$, seguido dos outros dois tratamentos com sacarose $80 \%$ + ácido ascórbico ou pectina, que não diferiram entre si. Guimarães et al. ${ }^{33}$ observaram que a desidratação em morangos sem pré-tratamento osmótico reduziu os teores de ácido ascórbico para 35,69 mg $100 \mathrm{~g}^{-1}$, resultados similares aos teores encontrados para o tratamento controle deste estudo. Nos estudos de Egea \& Lobato ${ }^{43}$ e Mendes et al.$^{41}$ em maçãs e laranjas desidratadas, as perdas de vitamina $\mathrm{C}$ diminuíram com a realização do processo osmótico como pré-tratamento para a secagem convectiva, corroborando o estudo.

Observa-se que os tratamentos adicionados de ácido cítrico, pectina e ácido ascórbico, além da sacarose, obtiveram maior concentração de compostos bioativos do que a amostra controle. De acordo com Falade \& Igbeka, ${ }^{44}$ isto ocorre devido ao tratamento osmótico, que é uma combinação de desidratação e de impregnação que minimiza as modificações negativas dos componentes dos alimentos frescos. Ou seja, é um processo de imersão de frutas e vegetais em sal, açúcar ou solução combinada, para reduzir o teor de água enquanto aumenta o teor de sólidos solúveis. ${ }^{26}$ Segundo Alakali et al. ${ }^{45}$ o agente desidratante mais comum para frutos é a sacarose, que também é considerada um ótimo agente osmótico, pois previne o escurecimento enzimático e a perda de aromas. Esta prevenção é devida à presença de uma camada do dissacarídeo, formada na superfície do produto desidratado, que constitui um obstáculo ao contato com o oxigênio, o qual minimiza ou impede o escurecimento enzimático, além de ter influência positiva sobre a manutenção da cor e das substâncias aromatizantes do alimento.

Neste sentido, a adição de sacarose pode estar envolvida em dois mecanismos que podem ter influenciado a retenção de compostos fenólicos e antocianinas. O primeiro envolve a reação de escurecimento enzimático; as enzimas responsáveis pelo escurecimento, especialmente peroxidase 
e polifenoloxidase, em contato com o oxigênio, causam a oxidação dos compostos fenólicos. Como este processo é minimizado pela formação do obstáculo citado anteriormente, a degradação dos compostos fenólicos pode ser evitada.

Um segundo mecanismo para a retenção dos compostos fenólicos quando se utiliza sacarose como pré-tratamento osmótico pode ser o efeito protetor dado pela complexação dos compostos fenólicos com moléculas de açúcares, formando complexos maiores que poderiam não atravessar a membrana celular ${ }^{46,47}$ Este efeito protetor da impregnação de açúcares já foi verificado em estudos anteriores para morango e kiwi em compostos como ácido ascórbico, clorofila e antocianinas. ${ }^{48}$

Além da sacarose, a adição de compostos como ácido ascórbico, ácido cítrico e pectina reduz a deterioração das frutas, mantendo sua qualidade. Esses compostos atuam como antioxidantes, aumentando a vida de prateleira de frutas, por meio da redução de reações de escurecimento, descoloração de pigmentos, perdas sensoriais e nutricionais. ${ }^{26}$ Possivelmente, a ação conjunta das substâncias adicionadas no pré-tratamento auxiliou na preservação dos compostos de interesse nutricional, o que pode ser concluído especialmente quando se compara o tratamento controle com os demais.

Segundo Calegaro et al., ${ }^{49}$ a manutenção da cor dos morangos durante o armazenamento é um atributo de qualidade desejado, pois o escurecimento dos frutos compromete seu aspecto visual e, assim, sua aceitação pelo consumidor. Os resultados obtidos para a coloração dos morangos desidratados estão expressos na tabela 4.

Tabela 4. Luminosidade (L) e ângulo hue ( ${ }^{\circ}$ hue) (média \pm desvio padrão) de morangos desidratados com diferentes tratamentos'. Guarapuava-PR, 2016.

\begin{tabular}{lcc}
\hline \multicolumn{1}{c}{ Tratamento } & Luminosidade $(\mathrm{L})$ & ${ }^{\circ}$ Hue \\
\hline Controle & $31,3 \pm 0,7^{\mathrm{cd}}$ & $34,6 \pm 3,6^{\mathrm{ab}}$ \\
$80 \%+$ ac cítrico & $31,4 \pm 1,1^{\mathrm{cd}}$ & $26,9 \pm 4,3^{\mathrm{bc}}$ \\
$80 \%+$ ac ascórbico & $32,6 \pm 0,8^{\mathrm{bc}}$ & $28,3 \pm 2,9^{\mathrm{abc}}$ \\
$80 \%+$ pectina & $34,2^{\mathrm{ab}} \pm 0,8^{\mathrm{ab}}$ & $20,3 \pm 4,2^{\mathrm{c}}$ \\
$60 \%+$ ac cítrico & $30,4 \pm 0,2^{\mathrm{d}}$ & $37,8 \pm 2,9^{\mathrm{a}}$ \\
$60 \%+$ ac ascórbico & $34,4 \pm 0,4^{\mathrm{ab}}$ & $30,7 \pm 3,2^{\mathrm{ab}}$ \\
$60 \%+$ pectina & $35,4 \pm 0,2^{\mathrm{a}}$ & $34,0 \pm 2,1^{\mathrm{ab}}$ \\
\hline
\end{tabular}

${ }^{1}$ Letras diferentes na coluna indicam diferença significativa pelo teste de Tukey $(\mathrm{p}<0,05) ; 80 \%=80 \%$ de sacarose; $60 \%=60 \%$ de sacarose. 
Com relação à coloração, verificou-se tendência ao menor escurecimento das amostras (aumento do valor L*) após a desidratação com 80 e $60 \%$ de sacarose + pectina e $60 \%$ de sacarose + ácido ascórbico, visto que os valores de L* variam de 0 (totalmente escuro) a 100 (claro). As mudanças de coloração (valor L) podem ser explicadas pela absorção de açúcares durante a osmose e a concentração desta durante a secagem, bem como pelo efeito da temperatura, que favorece processos de escurecimento, evitados em parte pela adição de açúcar e de ingredientes conservadores. Reis et al. ${ }^{50}$ verificaram que a coloração das frutas vermelhas tornou-se vermelho amarronzada com a desidratação por diferentes tratamentos, com média de L similar às encontradas neste estudo. A avaliação da cor é um importante parâmetro, pois é através dela que se pode avaliar se o fruto realmente atingiu ou não condições ideais de comercialização. De acordo com El-Aouar et al., ${ }^{51}$ quando combinada a secagem convencional ao processo osmótico com adição de agentes conservadores, há maior retenção da cor natural do produto, preservação de componentes voláteis e minimização do encolhimento, além de redução do consumo de energia durante a etapa de secagem.

O ângulo de cor Hue indica a tonalidade de um produto $\left(0^{\circ}\right.$ vermelho, $90^{\circ}$ amarelo, $180^{\circ}$ verde, $\left.270^{\circ} \mathrm{azul}\right) .^{52}$ No presente estudo, as amostras ficaram mais próximas ao $0^{\circ}$, indicando coloração vermelha. O tratamento com sacarose $80 \%$ + pectina foi o que mais se aproximou de $0^{0}$, tendo a coloração vermelha mais intensa, porém não diferindo dos tratamentos $80 \%$ sacarose + ácido ascórbico e $80 \%$ sacarose + ácido cítrico. Os tratamentos sacarose $80 \%$ + ácido cítrico, sacarose $80 \%$ + ácido ascórbico, sacarose $60 \%$ + ácido ascórbico, sacarose $60 \%$ + pectina e o tratamento controle não diferiram entre si.

Mendes et al. $^{41}$ apontam em seus estudos que frutas desidratadas, como a laranja, apresentam maiores índices de saturação durante o processo, ou seja, cores mais fortes e intensas em virtude do aumento na concentração de sólidos.

\section{Conclusão}

Os resultados indicaram que o tratamento osmótico com $80 \%$ de sacarose e o acréscimo de ácido ascórbico ou pectina seguido de desidratação foi bem aceito pelos provadores. A adição destes ingredientes melhorou a aceitação do consumidor frente à cor, aroma e textura do produto, quando comparado ao morango desidratado sem pré-tratamento (controle). O maior teor de sólidos solúveis foi verificado para o tratamento $80 \%$ sacarose + pectina, assim como a maior relação SS/ AT, que pode ter influenciado a preferência dos provadores para este tratamento, porém não é fator condicionante para a preferência, visto que o tratamento $80 \%$ sacarose + ácido ascórbico apresentou boa aceitabilidade e relação SS/AT mais baixa.

Quanto ao teor de compostos fenólicos, antocianinas e ácido ascórbico, os tratamentos com adição de sacarose e ingredientes conservadores, como o ácido ascórbico, ácido cítrico e pectina, 
apresentaram maiores teores em relação ao tratamento controle, principalmente aqueles com

$80 \%$ sacarose. Os tratamentos com $80 \%$ sacarose + pectina ou ácido ascórbico ou ácido cítrico foram os que apresentaram coloração vermelha mais intensa em relação aos demais tratamentos.

Nesse sentido, a elaboração do morango desidratado com pré-tratamento de $80 \%$ sacarose + ácido ascórbico ou pectina é uma boa alternativa de conservação de morangos, podendo ser empregada por pequenos agricultores, além de preservar compostos de interesse nutricional e a cor.

\section{Agradecimentos}

Os autores agradecem a Bruna Tais Noronha, Kelly Cristiane Michalichen e Priscila Lumi Ishii, pelo auxílio e colaboração durante a pesquisa e realização da parte experimental.

\section{Colaboradores}

Alves V, Schwarz K e Luz FR participaram da concepção e desenho do estudo, da análise e interpretação dos dados e elaboração do artigo até a versão final. Resende JTV deu suporte ao estudo, disponibilizando a estrutura e equipamentos para realização da parte experimental. Vieira RLD e Bennemann GD, da revisão crítica de conteúdo.

Conflito de Interesses: Os autores declaram não haver conflito de interesses.

\section{Referências}

1. Instituto de Tecnologia dos Alimentos. Conservação do morango. Campinas: ITAL; 1978. 212 p.

2. Han C, Lederer C, McDaniel M, Zhao Y. Sensory evaluation of fresh strawberrie (Fragaria ananassa) coated with chitosan-based edible coatings. Journal of Food Science. 2005; 70(3):S172-S178.

3. Oszmianski J, Wojdylo AA. Comparative study of phenolic content and antioxidant activity of strawberry puree, clear, and cloudy juices. European Food Research and Technology. 2009; 228(4):623-631.

4. Ariza MT, Reboredo-Rodríguez P, Mazzoni L, Forbes-Hernández TY, Giampiere F, Afrin S, et al. Strawberry achenes are an important source of bioactive compounds for human health. Int J Mol Sci. 2016; 17(7):1103.

5. Giménez G, Andriolo J, Godoi R. Cultivo sem solo do morangueiro. Ciência Rural. 2008; 38(1):273-279.

6. Lima F. Pesquisa pretende desenvolver morango brasileiro. 2015. Agron - Agronegócio Online [Internet]. 16 ago. 2018. [acesso em: 10 dez. 2017]. Disponível em: https://www.agron.com.br/ publicacoes/noticias/ciencia-e-tecnologia/2015/08/22/045421/pesquisa-pretende-desenvolvermorango-brasileiro.html 
7. Basílio MP, Charbel ALT, Ferreira AG. Avaliação da secagem de morangos em estufa e em secador híbrido solar-elétrico. Revista Acadêmica Conecta FASF [Internet]. 2016; 1(1). Disponível em: http:// revista.fasf.edu.br/index.php/conecta/article/view/16/pdf

8. Dias MC. Desperdício de alimentos. Correio Braziliense [Internet]. 31 ago. 2003. [acesso em: 10 dez. 2017]. Disponível em: http://www.consciencia.net/2003/09/06/comida.html

9. Duarte Filho JD, Antunes LEC, Pádua JG. Cultivares. Informe Agropecuário. 2007; 28(236):20-23.

10. Del-Valle V, Muñoz PH, Guarda A, Galotto MJ. Development of a cactusmucilage edible coating (Opuntia ficus indica) and its application to extend strawberry (Fragaria ananassa) shelf-life. Food Chemistry 2005; 91(4): 751-756.

11. Cia P, Bron IU, Valentini SRT, Pio R, Chagas EA. Atmosfera modificada e refrigeração para conservação pós-colheita da amora-preta. Bioscience Journal. 2007; 23(3): 11-16.

12. Vargas M, Albors A, Chiralt A, González-Martínez C. Quality of coldstored strawberries as affected by chitosan-oliec acid edible coatings. Postharvest Biology and Technology. 2006; 41:164-171.

13. Quinato EE, Degáspari CH, Vilela RM. Aspectos nutricionais e funcionais do morango. Visão Acadêmica [Internet]. 2007; 8(1). Disponível em: https://revistas.ufpr.br/academica/article/view/11660

14. Celestino SMC. Princípios de secagem de alimentos. Planaltina, DF: Embrapa Cerrados; 2010.

15. Souza Neto MA, Maia GA, Lima JR, Figueiredo RW, Souza Filho MSM, Lima AS. Desidratação osmótica de manga seguida de secagem convencional: avaliação das variáveis de processo. Ciência e Agrotecnologia. 2005; 29(5):1021-1028.

16. Kluge RA, Nachtigal JC, Fachinello JC, Bilhalva AB. Fisiologia e manejo pós-colheita de frutas de clima temperado. 2. ed. Campinas: Livraria Rural; 2002. 214 p.

17. Costa ARS, Ferreira SR. Sistema de secado solar para frutos tropicais. Informacíon Tecnológica. 2007; 18(5):49-58.

18. Pesquisa Industrial [Internet]. Rio de Janeiro: IBGE. v. 30, n. 2. 2011. [acesso em: 9 dez. 2017]. Disponível em: http://biblioteca.ibge.gov.br/visualizacao/periodicos/1719/pia_2011_v30_n2_ produto.pdf

19. Brasil. Ministério da Saúde. Secretaria da Vigilância Sanitária. Resolução CNNPA n.12, 23 de julho de 1978. Normas Técnicas Especiais. Diário Oficial da União 24 jul. 1978.

20. Dutcosky SD. Análise sensorial de alimentos. 3. ed. Curitiba: Champagnat; 2011.

21. Teixeira E, Meinert E, Barbetta PA. Análise sensorial de alimentos. Florianópolis: UFSC; 1987. 180 p.

22. Association of Official Analitical Chemists. Official methods of analisys of AOAC International. Gaithersburg, MD: AOAC; 1984.

23. Woisky RG, Salatino A. Analysis of propolis: some parameters and procedures for chemical quality control. Journal of Apicultural Research. 1998; 37(2):99-105.

24. Giusti MM, Wrolstad RE. Anthocyanins: characterization and measurement with uv-visible spectroscopy. In: Wrolstad RE. Current protocols in food analytical chemistry. New York: John Wiley and Sons; 2001. p. 121-130. 
25. Benassi MT, Antunes AJ. A comparison of methaphosphoric and oxalic acids as extractant solutions for the determination of vitamin $\mathrm{C}$ in selected vegetables. Brazilian Archives of Biology and Technology. 1988; 31:507-513.

26. Campo C. Desidratação osmótica de morangos cv. Aromas [Trabalho de Conclusão de Curso]. [Bento Gonçalves]: Instituto Federal de Educação, Ciência e Tecnologia; 2012.

27. Nigihan M, Karaashan M. Anthocyanin profile of strawberry fruit as affected by extraction conditions. International Journal of Food Properties. 2017; 20:S2313-S2322.

28. Fernandes TN. Relação entre a adição de sacarose e pectina, comportamentos reológicos e dinâmicos do congelamento e descongelamento de polpas de morango e abacaxi [dissertação]. [Lavras]: Universidade Federal de Lavras; 2008.

29. Aplicações do ácido cítrico na indústria de alimentos. Food Ingredients Brasil [Internet]. 2014. Disponível em: http://www.revista-fi.com/materias/402.pdf.br

30. Balke ME, Oliveira HT, Steffens C, Valduga E, Soares ABJ, Steffens J, Soares MBA. Avaliação Sensorial de pêssegos obtidos por diferentes métodos de secagem. Congresso Brasileiro de Engenharia Química. Anais do Congresso Brasileiro de Engenharia Química; 2014; Florianópolis. Florianópolis: COBEQ; 2014. 8 p.

31. Azevedo SMC. Estudos de taxa de respiração e de fatores de qualidade na conservação de morango fresco [dissertação]. [Lisboa]: Universidade Aberta; 2007.

32. Kader AA. Quality and its maintenance in relation to postharvest physiology of strawberry. Oregon: Timber Press; 1991. p. 145-152.

33. Guimarães AG, Oliveira CM, Vieira G, Pinto NAVD. Qualidade físicas e químicas de morango passa em diferentes embalagens. Engenharia na Agricultura. 2014; 22(4):306-316.

34. Thé PMP, Carvalho VD, Abreu CMF, Nunes RF, Pinto NAVD. Efeito da temperatura de armazenamento e do estádio de maturação sobre a composição química de abacaxi cv. Smooth cayene L. Ciência e Agrotecnologia. 2001; 25(2): 356-363.

35. Franco BDGM, Landgraf M. Microbiologia de alimentos. São Paulo: Atheneu; 2003.182 p.

36. Torreggiani D, Bertolo G. Osmotic pre-treatments in fruit processing: chemical, physical and structural effects. Journal of Food Engineering. 2001; 49:247-253.

37. Pereira LM. Acondicionamento de goiabas minimamente processadas por desidratação osmótica em embalagens sob atmosfera modificada [dissertação]. [Campinas]: Faculdade de Engenharia de Alimentos, Universidade Estadual de Campinas; 2002.

38. Colpo LP. Avaliação da capacidade antioxidante e conteúdo de compostos fenólicos de frutas vermelhas submetidas a processamentos por calor (micro-ondas, sous vide, fervura e desidratação) [dissertação]. [São Leopoldo]: Faculdade de Nutrição, Universidade do Vale do Rio dos Sinos; 2015.

39. El-Aquar AA. Avaliação do processo combinado de desidratação osmótica e secagem na qualidade de cubos de mamão formosa (Carica papaya L.) [dissertação]. [Campinas]: UNICAMP; 2001.

40. El-Aquar ÂA, Murr FEX. Estudo e modelagem da cinética de desidratação osmótica do mamão formosa (Carica papaya L.). Ciênc. Tecnol Aliment. 2003; 23(1):69-75. 
41. Mendes GRL, de Freitas CH, Scaglioni PT, Schmidt CG, Furlong EB. Condições para desidratação osmótica de laranjas e as propriedades funcionais do produto. Revista Brasileira de Engenharia Agrícola e Ambiental. 2013; 17(11):1210-1216.

42. Shigematsu E, Eik NM, Kimura M, Mauro MA. Influência de pré-tratamentos sobre a desidratação osmótica de carambolas. Ciênc. Tecnol Aliment. 2005; 25(3):536-545.

43. Egea MB, Lobato LP. A desidratação osmótica como pré-tratamento para frutas e hortaliças. Rev Inst Adolfo Lutz. 2014; 73(4): 316-324.

44. Falade KO, Igbeka JC. Osmotic dehydration of tropical fruits and vegetables. Food Reviews International. 2007; 23: 373 - 405.

45. Alakali JS, Ariahu CC, Nkpa NN. Kinetics of Osmotic Dehydration of Mango. Journal of Food Processing and Preservation. 2006; 30(5): 597-607.

46. Heng K, Guilbert S, Cuq JL. Osmotic dehydration of papaya: influence of process variables on the product quality. Sciences des Aliments. 1990; 10: 831-848.

47. Taku MA, Yukiko S, Masaru W, Kiyohiko T, Toshiyuki N, Hideo H, Kunio A. Dehydration of $\mathrm{D}$-glucose in high temperature water at pressures up to $80 \mathrm{MPa}$. The Journal of Supercritical Fluids. 2007; 40(3):381-388.

48. Bobbio FO, Bobbio PA. Introdução à química de alimentos. 3. ed. São Paulo: Livraria Varela; 2003.

49. Calegaro JM, Pezzi E, Bender RJ. Utilização de atmosfera modificada na conservação de morangos em pós-colheita. Pesquisa Agropecuária Brasileira. 2002; 37(8):1049-1055.

50. 46. Reis KC, Siqueira HH, Alves AP, Silva DJ, Lima LC. O. Efeito de diferentes sanificantes sobre qualidade de morango cv. Oso Grande. Ciência e Agrotecnologia. 2008; 32(1):196-2002.

51. El-Aouar AA, Azoubel PM, Barbosa Junior JL, Murr FEX. Influence of the osmotic agent on the osmotic dehydration of papaya (Carica papaya L.). Journal of Food Engineering. 2006; 75:267-274.

52. Garcia EL, Carmo EL, Pádua JG, Leonel M. Potencialidade de processamento industrial de cultivares de batatas. Ciência Rural. 2015; 45(10):1742-1747. 
